\title{
Visita al renaciente, antes casi olvidado, tejido graso pardo
}

\author{
Arturo Orrego M, MD.
}

Médico Internista Endocrinólogo, Miembro Honorario de la Asociación Colombiana de Endocrinología, Diabetes y Metabolismo.

Fecha de recepción: 05/02/2015

Fecha de aceptación: 23/09/2015

$\mathrm{E}$ l tejido adiposo juega un papel central en la nutrición, el balance energético y la salud en los humanos. Existen dos tipos de tejido adiposo: el blanco (TAB) y el pardo (TAP). El TAB conserva la energía, mientras que el TAP la utiliza. El exceso de nutrición y la inactividad física dan origen a un incremento del TAB y a la obesidad. En cambio el TAP es termogénico, debido a una proteína única desacopladora (UCP1). Esta proteína localizada en la parte interna de la membrana mitocondrial desacopla la respiración mitocondrial, produciendo tanto energía como calor. Esta propiedad esencial protege a los animales de la hipotermia ${ }^{(1)}$.

La creencia tradicional de que el TAP sólo existe en infantes y no en adultos retrasó la investigación en humanos. Pero el descubrimiento de que la grasa del adulto presentaba una alta actividad metabólica como lo demostraba la tomografía por emisión de positrones (TEP) hizo que los investigadores se interesaran nuevamente en el TAP y que se reiniciara la investigación sobre este tejido, su identificación, la prevalencia, regulación, localización, abundancia y su importancia en el humano ${ }^{(2-9)}$.

\section{Abreviaturas utilizadas:}

RA, receptores adrenérgicos ; TAP, tejido adiposo pardo; IMC, índice de masa corporal; C/EBP,CCAAT, activadores de proteína unidoras; $\mathrm{TIF}$, termogénesis inducida por el frio; TC, tomografía computarizada; TID, termogénesis inducida por dieta; EU, energía utilizada; ${ }^{18}$ FDG, ${ }^{18}$ Fluordeoxyglucosa; FGF21, factor 21 de crecimiento de los fibroblastos; TIR termografía infrarroja; RM, resonancia magnética; TEP, tomografía por emisión de positrones; PGC- $1 \alpha$, PPAR- $\gamma$ coactivadora $1 \alpha$; PPAR- $\gamma$, receptor proliferador activado peroxisome gamma; PRMD16, PRD1-BF-RiZ1 dominios homólogos que contienen proteínas-16; SNS, sistema nervioso simpático; HT, hormonas tiroideas; UCP1, proteínas no acopladas 1; TAB tejido adiposo blanco.
A pesar de que en 1551, Gessner identificó la grasa parda en animales que hibernaban, sólo en 1960 se inició la era dorada de la investigación de esta grasa ${ }^{(10-18)}$ que alcanzó su máximo éxito después de la década de los 80 , cuando se obtuvo la evidencia inequívoca de que el TAP aún existía en adultos, lo que desbordó el interés en la investigación sobre este tejido graso.

Lee y colaboradores detallaron las investigaciones más importantes realizadas y sus resultados en humanos sobre el TAP, desde $1902^{(19)}$.

En 1960 se descubrió que el TAP era regulador de la termogénesis ${ }^{(13-18)}$. Se propuso que el TAP era un tejido productor de calor en animales y en infantes humanos, capaz de defender a los recién nacidos de la hipotermia. El TAP es histológica $\mathrm{y}$ funcionalmente distinto al TAB, y la presencia de un transportador facultativo de protones UCP1 en este último tejido le confiere la habilidad única de generar calor a través del desacoplamiento respiratorio ${ }^{(20)}$. Heaton encontró que el TAP persistía hasta la octava década de la vida. Estos hallazgos sugirieron la hipótesis que la falta del TAP podría contribuir a la presentación de la obesidad en el adulto ${ }^{(21-25)}$, lo que originó un incremento de tres veces más publicaciones sobre este tejido adiposo, entre 1980 y 1982.

Durante este periodo temprano, la investigación sobre el TAP se limitó a examinar depósitos de grasa alrededor de la adrenal, una localización accesible durante la cirugía electiva abdominal. Este acercamiento menospreció el TAP extrabdominal, olvidando la abundancia y frecuencia en adultos de esta grasa en estas regiones. Hasta este momento no existía un consenso para soportar un papel definitivo de la grasa parda en la homeostasis de la energía en adultos ${ }^{(26,27)}$, lo que llevó a Rothwell y Stock a dudar de la existencia de la grasa parda en humanos ${ }^{(28)}$. Se reconoció que había serias dificultades para identificar depósitos del TAP en humanos y que la controversia continuaría hasta que se descubrieran métodos no invasivos para cuantificar esta grasa y estar en capacidad de calcular la capacidad termogénica de estos tejidos ${ }^{(26,28)}$.

Se necesitaron dos décadas más para que aparecieran los instrumentos no invasivos para detectar y cuantificar el TAP como la tomografía de emisión de positrones (TEP) ${ }^{(29)}$, método que hizo renacer el entusiasmo en la investigación metabólica del $\mathrm{TAP}^{(29)}$. 


\section{Características de ambos tejidos grasos}

La célula adiposa blanca se caracteriza por su apariencia redonda con una sola vacuola de grasa que desplaza el núcleo hacia la periferia. En cambio, la célula de grasa parda se identifica por su forma poligonal, de tamaño menor, un núcleo central y numerosas vacuolas de grasa, pequeñas, dando apariencia de ser multiloculares, presentan una alta densidad de mitocondrias, comparable a la de los cardiomiocitos. En cambio, en las células grasas blancas, las mitocondrias existen en menos cantidad. El TAP es abundante en vasos y nervios y con una rica suplencia de células mesenquimales perivasculares que son la fuente de los preadipocitos. La abundancia de mitocondrias que contienen enzimas de la cadena de los citocromos compuestos de hierro como cofactor, aunado a la rica vascularización son la causa del color rojo oscuro (pardo), típico del TAP que contrasta con el color pálido del TAB.

\section{Origen}

Debido a que ambos tejidos grasos el TAB y el TAP se caracterizan por la presencia de vacuolas de lípidos, se ha creído que ambos tejidos grasos tienen un origen común. Con estudios en roedores se ha demostrado que el TAB y el TAP se originan en células madres mesenquimatosas, las cuales pueden diferenciarse en adipocitos, osteoblastos, condrocitos y mioblastos ${ }^{(30)}$. La diferenciación de las células grasas, pardas y blancas, comienza con la adipogénesis, un proceso que culmina con la acumulación intracelular de lípidos, controlado por varios factores, entre los cuales, PPAR- $\gamma$ es el más crítico, factor esencial para la adipogénesis de ambos tejidos grasos, el TAB y el TAP. Tanto las células adiposas adultas, las blancas y las pardas expresan altos niveles de PPAR- $\gamma^{(31,32)}$. Aunque se han identificado muchos activadores y represores de la adipogénesis, la mayoría modulan la expresión de la actividad del PPAR- $\gamma^{(33,34)}$. Aislados de los depósitos de células pardas y blancas, los precursores de los fibroblastos se diferencian en adipocitos pardos o blancos, respectivamente, en la ausencia de sustancias inductoras ${ }^{(35)}$. En humanos, tal diferenciación espontánea no ocurre sin inducción con agentes adipocinéticos como la dexametasona (figura 1).

\section{Adipogénesis de las células pardas}

PPAR- $\gamma$ y el coativador- $1 \alpha$ (PGC- $1 \alpha$ ) son los reguladores más importantes de la biogénesis mitocondrial. Los niveles de PGC-1 $\alpha$ en los adipocitos pardos están ampliamente en relación con la producción de energía ${ }^{(36)}$. En humanos, el ARN mensajero de PGC- $1 \alpha$ se expresa de 2 a 15 veces más frecuentemente en las células pardas que en los adipocitos blancos (tabla 1).

PGC-1 $\alpha$ no solamente está aumentando en el TAP sino que decide la riqueza del TAP dentro del TAB. Aunque la expresión de PGC- $1 \alpha$ es baja en el TAB puede ser estimulado por la ex- posición al frío y por los agentes beta adrenérgicos ${ }^{(37)}$. Existen evidencias recientes de que PGC- $1 \alpha$ es un factor clave en la regulación de la adipogénesis de las células pardas ${ }^{(38,39)}$.

\section{Origen de las células pardas}

Aunque PGC-1 $\alpha$ juega un papel central en la formación de las células pardas, su ablación no produce la reducción de la masa de estas células, lo que sugiere que existen otros factores que son indispensables en la diferenciación de las células pardas.

Se ha sugerido durante muchos años que los adipocitos pardos y blancos son derivados de una célula madre común. Sin embargo, evidencias recientes demostraron que ambas células se originan en precursores diferentes ${ }^{(40)}$.

Últimamente existe evidencia de que los adipocitos pardos se originan en una célula madre tripotente que da origen a la dermis, los adipocitos pardos y el músculo esquelético ${ }^{(19)}$. Consistente con este hallazgo, los adipocitos pardos de la región interescapular y el tejido muscular expresaron Mүf5, gen que se ha asumido se expresa únicamente en los precursores de las células musculares ${ }^{(19)}$. Los adipocitos pardos están presentes en los músculos esqueléticos de roedores y humanos ${ }^{(40)}$ (figura 1).

Tabla 1. Hallazgos metabólicos del TAP, en humanos adultos

\begin{tabular}{|c|c|c|c|c|}
\hline $\begin{array}{l}\text { Autor } \\
\text { (ref) }\end{array}$ & Año & $\mathbf{n}$ & $\begin{array}{l}\text { Hallazgos } \\
\text { metabólicos }\end{array}$ & Magnitud \\
\hline Virtanen ${ }^{(5)}$ & 2009 & 5 & $\begin{array}{l}\text { Captación de } \\
\text { glucosa por el TAP } \\
\text { estimulado con frío }\end{array}$ & $\begin{array}{c}12,2 \\
\mu \mathrm{mol} / 100 / \mathrm{min}\end{array}$ \\
\hline Yoneshiro(19) $^{(19)}$ & 2011 & 13 & $\begin{array}{l}\text { Deficiencias en la } \\
\text { energía utilizada } \\
\text { con la exposición al } \\
\text { frío en individuos } \\
\text { con TAP+ y negativo }\end{array}$ & $+368 \mathrm{Kcal} / \mathrm{d}$ \\
\hline Orava $^{(19)}$ & 2011 & 27 & $\begin{array}{l}\text { Con la exposición } \\
\text { al frío hubo } \\
\text { Incremento en } \\
\text { la captación de } \\
\text { glucosa por el TAP } \\
\text { Diferencia en la } \\
\text { energía utilizada } \\
\text { Con exposición al } \\
\text { frío en individuos } \\
\text { TAP positivos y } \\
\text { negativos }\end{array}$ & $\begin{array}{c}+8,0 \\
\mu \mathrm{mol} / 100 \mathrm{~g}\end{array}$ \\
\hline Quellet $^{(19)}$ & & 6 & $\begin{array}{l}\text { Captación de la } \\
\text { glucosa por el TAP } \\
\text { estimulado por } \\
\text { el frío } \\
\text { Diferencias en la } \\
\text { energía utilizada } \\
\text { por el TAP expuesto } \\
\text { al frío y en } \\
\text { ambiente cálido }\end{array}$ & $\begin{array}{l}10,8 \mu \mathrm{mol} / \mathrm{min} \\
+2001 \mathrm{Kcal} / \mathrm{d}\end{array}$ \\
\hline
\end{tabular}




\section{Adipocitos brite}

Evidencia creciente ha demostrado que los adipocitos pardos tienen diferentes orígenes. Esta evidencia deriva de los estudios que informaron de la adipogénesis parda dentro de los adipocitos blancos. Los adipocitos pardos encontrados dentro el TAB se conocen como brite (brown-in-white) ${ }^{(19)} \mathrm{o}$ adipocitos beige ${ }^{(19)}$. En humanos, las células madres (stem cell) pluripotentes y los agonistas PPAR- $\gamma$ activaron un programa de grasa parda ${ }^{(19)}$. En, los adipocitos blancos de humanos la expresión PGC- $1 \alpha$ mediada por adenovirus aumentó la presencia de UCP1 ${ }^{(19)}$. Los preadipocitos obtenidos por biopsia de la grasa supraclavicular humana y cultivados muestran abundancia de expresión de UCP1 durante la adipogénesis parda ${ }^{(19)}$. Estos adipocitos diferenciados pueden exhibir una sola vacuola de grasa rodeada por varias vacuolas más pequeñas o estar repleta de vacuolas de grasa multilobuladas, como se aprecia en las células clásicas pardas ${ }^{(19)}$ (figura 1).

Figura 1. Origen de los tejidos adiposo blanco, beige/brite y pardo. Las "células madre" mesenquinales son multipotentes que dan origen a diferentes tipos de adipocitos, además a condrocitos, osteoblastos y miocitos; las células que expresan $\mathrm{M} \gamma \mathrm{f5}$, considerado antes como marcador miogénico, pueden diferenciarse para producir adipocitos pardos o miocitos. Alternativamente las células privadas del marcador $\mathrm{M} \gamma \mathrm{f5}$ pueden dar origen a adipocitos blancos o beige/brite. Las etapas finales en la diferenciación de los tres tipos de adipocitos están controladas por una serie de factores de transcripción que incluyen PPARy y C/EBP $\alpha,-\beta$ y $\delta$. Los adipocitos pardos también son enriquecidos por el factor coactivador de transcripción PGC1- $\alpha$, que dirige la expresión de moléculas claves regulatorias en la biogénesis mitocondrial, en respuesta a estímulos externos tales como la exposición al frío.

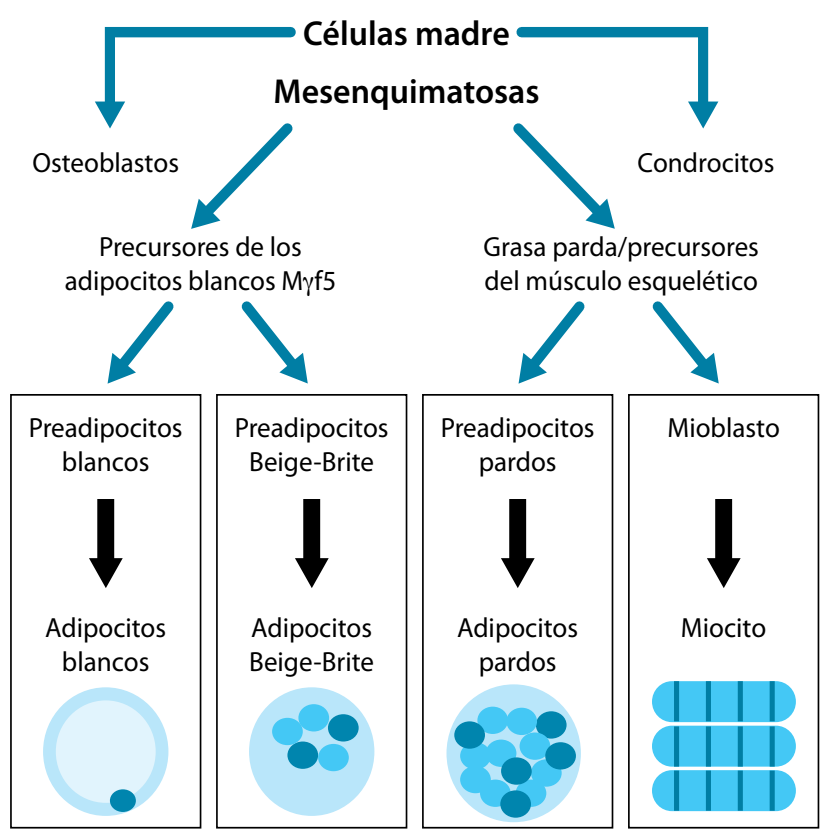

Así PPAR- $\gamma$ y PGC- $1 \alpha$ parecen jugar un papel importante en la adición de componentes de la grasa parda a las células adiposas blancas humanas.

El estudio de la aclimatización de roedores en temperaturas frías no mostró variaciones en la cantidad de células adiposas, ni del ADN, lo que sugiere una directa trasformación (trasdiferenciación) de las células adiposas blancas a pardas ${ }^{(19)}$. No está claro si todo el tejido adiposo blanco tiene el potencial de trasformación en tejido adiposo pardo. Se encontró que el UCP1 se expresaba solamente en la grasa parda de los depósitos situados en las regiones interescapulares, cervical, axial y mediastinal, sitios clásicos de localización del $\mathrm{TAP}^{(19)}$. Se cree que este hallazgo está en relación con el sistema nervioso simpático, canal aferente de la exposición al frío; el incremento de las células adiposas brite también se manifestó después de la administración crónica de agonistas beta ${ }^{(19)}$.

Los adipocitos pardos están presentes en los músculos de roedores y humanos. Las células multipotentes, que expresaron en las superficies marcadores CD34, aisladas de músculos esqueléticos humanos, se diferenciaron en adipocitos $\operatorname{pardos}^{(19)}$.

\section{Preguntas no resueltas}

Se ha propuesto que el TAP es más parecido durante su desarrollo al músculo esquelético que el TAB. Los adipocitos pardos clásicos expresan más Mүf5, en cambio los adipocitos blancos y los brite, no. Este tópico es más difícil de contestar, ya que existen evidencias que sugieren que los adipocitos pardos y brite pueden originarse en células hematopoyéticas dentro de la médula ósea y que es posible encontrar el marcador M $\gamma f 5$ en el TAB $^{(19)}$.

\section{Fisiología de los adipocitos pardos Localización}

Los mayores depósitos de adipocitos pardos, en roedores, están localizados en la región interescapular. Otros depósitos están situados cerca a los vasos, en la región cervical, axilar y paravertebral y en la proximidad de las vísceras torácicas y abdominales. En contraste, los adipocitos pardos del humano están localizados en la nuca, tórax, abdomen y yuxtapuestos a las vísceras profundas (corazón, pulmones, riñones, adrenales e intestinos) y a lo largo de los grandes vasos (carótidas, aorta, pulmonar y mesentéricos) (figura 2).

A pesar de la evidencia de que en humanos el TAP cervical, paravertebral, paraórtico, perirrenal y periadrenal existía durante toda la vida, la ausencia del TAP interescapular con la edad hizo suponer que el TAP desaparecía en la edad adulta ${ }^{(19)}$.

\section{Imaginogía por TEP}

La tomografía por la emisión de positrones (TEP) fue introducida en los años 80. La TEP, unida a la TAC (tomografía axial computarizada), localizaron los depósitos de tejido adi- 
Figura 2. TAP en humanos, distribución del TAP revelado por TEP y por histología

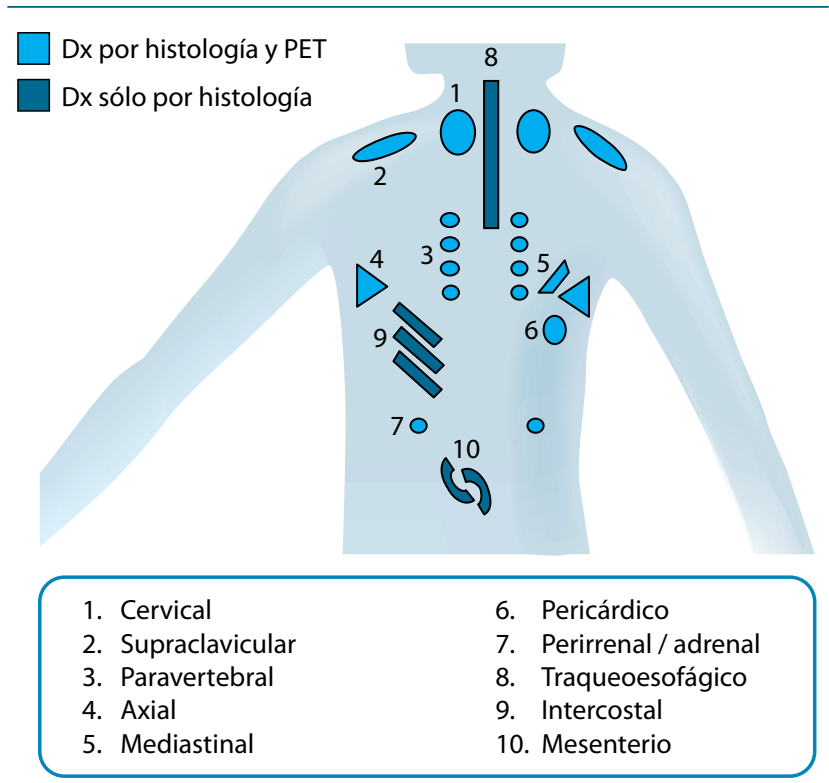

poso pardo en mayor proporción en las zonas supraclaviculares y mediastinales en humanos ${ }^{(2,3)}$.

Depósitos más pequeños se encontraron en la axila, epicardio, en regiones paravertebral, perirrenal y periadrenal(25). Ciertas zonas positivas para adipocitos pardos son detectables por biopsia, pero no por la TEP, intercostales, tráquea, esófago y mesentéricas. Se sugiere que las regiones no detectadas por la TEP, pero sí por biopsia son fisiológicamente inactivas ${ }^{(19)}$.

\section{Avidez de la grasa parda}

La evidencia de que la grasa que capta el 18 fluordeoxiglucosa $\left({ }^{18} \mathrm{FDG}\right)$ es TAP la confirma la histología y los estudios moleculares de genes responsables del desacoplamiento respiratorio celular (UCP1) por un incremento de la actividad de la deyodasa (DIO2), y por una mayor inervación adrenérgica ${ }^{(3-5,7)}$. Por diferentes estudios en humanos, que no detallamos, se comprobó la presencia mixta de TAP, TAB y posiblemente grasa brite en ciertos depósitos evaluados ${ }^{(19)}$.

La prevalencia de la grasa parda en humanos puede ser estudiada indirectamente por TEP-TAC o por análisis histológico de los depósitos de grasa.

Algunos estudios han demostrado que el diagnóstico convencional de adipocitos pardos mediante TEP-TAC tiene una reproducibilidad subóptima, por lo cual la evaluación de la prevalencia basada en un solo TEP-TAC puede llevar a conclusiones falsas $^{(19)}$. Más recientemente, entre 2.934 pacientes estudiados con TEP-TAC para detectar grasa parda ${ }^{(3)}$, se encontraron 250 pacientes con TAP, dando una aparente prevalencia de 8,5\%. Entre los pacientes con TAP, 145 fueron escaneados más de una vez. En estos pacientes, mientras más gammagrafías con TEPTAC se obtenían, mayores eran los casos positivos, $8 \%$ para 2 gammagrafías y $65 \%$ para 4 . En otras palabras, únicamente 1 de cada 8 pacientes con TAP tendrá una gammagrafía positiva si es estudiado una vez más. Esta probabilidad da origen a una prevalencia del 64\%, 8 veces más alta que la previamente publicada basada en estudios únicos en cohortes similares ${ }^{(3)}$.

El análisis anterior subestima la insensibilidad del TEPTAC convencional y sugiere dos preguntas 1) ¿Cuáles factores determinan la positividad del TEP-TAC? 2) ¿Puede existir TAP en individuos negativos? La primera pregunta ha sido contestada indirectamente con la TEP, previa estimulación con el frío, la última pregunta se ha tratado de resolver con la biopsia del tejido graso negativo con TEP.

\section{TEP estimulado con el frío}

La exposición a temperaturas entre $16^{\circ} \mathrm{C}$ y $19^{\circ} \mathrm{C}$ a individuos durante 1 a 2 horas convierte la TEP en positiva entre el $34 \%$ y el $96 \%(7,6,18,19)$, positividad que disminuye significativamente con la edad $^{(19)}$ (tabla 1).

Aunque la exposición al frío durante cierta temperatura sensibiliza la TEP-TAC para la detección del tejido adiposo pardo, dicha combinación es incapaz de determinar la verdadera prevalencia de este tejido adiposo. Esto es debido a que a esta técnica le falta sensibilidad o especificidad para discriminar el TAP de otros tejidos metabólicamente activos. Únicamente un examen directo de la grasa puede definir la duda.

\section{Examen tisular}

Dos estudios han definido la prevalencia de tejido adiposo pardo utilizando la biopsia mediante cirugía ${ }^{(4,6)}$.

La localización de los depósitos de grasa influenciará los resultados, debido a que la grasa parda se distribuye en áreas anatómicas específicas ${ }^{(4,6)}$.

Zingaretti y colegas ${ }^{(6)}$ hallaron que el 33\% de las muestras fueron positivas para tejido adiposo pardo, obtenidas de la grasa peritiroidea. La región supraclavicular es donde más frecuentemente se encuentra tejido adiposo pardo ${ }^{(4)}$. Hubo una enorme variabilidad biológica en la abundancia de TAP entre los individuos. La TEP-TAC fue positiva únicamente en 3 de 17 pacientes y se encontraron ocasionalmente pacientes positivos para TAP, a pesar de gammagrafía negativa ${ }^{(4)}$.

La exposición al frío convierte más del $80 \%$ de las TEP-TAC negativas a positivas, en presencia de grasa parda. Debido a que la existencia de TAP es 20 veces más frecuente en la TEP positiva que en la negativa, es probable que la exposición al frío estimule la actividad de la grasa parda, pero es improbable que se deba a hiperplasia del TAP en tan corto tiempo de exposición $^{(4,19)}$. De acuerdo con la reproducibilidad de los estudios gamagráficos, el hecho de que los pacientes puedan ser TEP positivo como negativos para TAP tan rápidamente, bajo ciertas condiciones ambientales, sugiere que deben existir otros factores reguladores distintos, diferentes al frío, capaces de cambiar el estado metabólico de la grasa parda ${ }^{(4,19)}$. 


\section{Factores reguladores}

\section{Exposición al frío}

Estudios en animales demostraron que la exposición al frío aumenta agudamente la actividad de la grasa parda ${ }^{(4,19)}$, mientras que la exposición crónica produce hiperplasia de este tejido adiposo ${ }^{(19)}$. La exposición al frío también induce trasformaciones morfológicas en el TAB. Unos autores ${ }^{(19)}$ identificaron la presencia de UCP1 inmunorreactiva propia de los adipocitos pardos después de la aclimatación al frío. Estos adipocitos pardos, en ausencia del incremento del número de adipocitos blancos, hizo pensar a los investigadores que estaban observando la trasformación de adipocitos blancos a pardos ${ }^{(19)}$.

En la práctica se ha utilizado la exposición al frío para tratar de activar metabólicamente los adipocitos pardos y hacerlos más sensibles a la detección con la TEP-TAC. Los métodos consisten en mantener los pacientes durante1 o 2 horas a temperaturas de 16 a $20^{\circ} \mathrm{C}$, antes de la inyección de la 18-fluordeoxiglucosa, después de lo cual los individuos se mantienen una hora adicional en el cuarto frío, antes de hacer la gammagrafía. Estos protocolos en ambiente frío aumentan hasta un $100 \%$ la detección del tejido adiposo pardo y la captación de la 18-fluordeoxiglucosa hasta 15 veces $^{(5,7,19)}$. En cambio, la gammagrafía con este isótopo a temperatura ambiente disminuye significativamente la detección del tejido graso pardo ${ }^{(19)}$. Otros protocolos, para descender la temperatura en el paciente utilizan la inmersión del individuo en agua fría o con contacto de las manos y pies con bloques de hielo, con resultados casi similares al enfriamiento del medio ambiente; como es de esperar, la identificación del tejido adiposo pardo es mayor durante el invierno ${ }^{(2,19)}$ pero no siempre ${ }^{(3,19)}$. En dos estudios con observaciones longitudinales realizados en los mismos individuos durante el verano y el invierno se sacó la conclusión de que la temperatura relacionada con las estaciones ejerce un efecto importante en la actividad de los adipocitos pardos ${ }^{(19)}$.

\section{Sistema nervioso simpático}

El sistema nervioso simpático aumenta la actividad del TAP. El frío incrementa la actividad del simpático, aumentando la noradrenalina circulante dos veces ${ }^{(19)}$. El TAP está densamente inervado por el simpático. El grado de termogénesis es controlado por vías iniciadas en el hipotálamo, el cual coordina la información termorreguladora e integra la respuesta reguladora del calor. Se ha hipotetizado que circuitos neurales en el hipotálamo controlan la producción de calor, regulando la actividad simpática en el tejido adiposo pardo ${ }^{(19)}$. Estudios recientes con neuroimágenes en humanos mostraron que los individuos con el TAP activado mostraban la región parietal derecha inferior (que gobierna la sensación de frío), hiperactiva; en cambio la ínsula izquierda (relacionada con el simpático) y el cerebelo derecho, que gobierna las funciones autonómicas, estaban hipometabólicos ${ }^{(19)}$ (tablas 1 y 2).

Tabla 2. Moléculas y agentes conocidos que Estimulan el Tejido Adiposo Blanco y el Tejido Adiposo Pardo

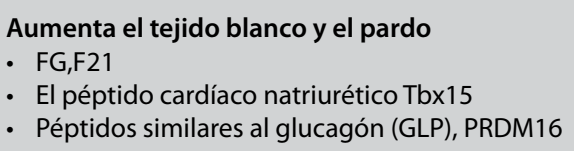

Aumentan sólo la masa del TAB

- Proteína morfogenética 7 del hueso

- Miostatina

- Twist-1
Únicamente aumenta la grasa blanca

- Inrisina

- Factor neurotrópico derivado del cerebro

- Cicloxigenasa-2

- VEGF-A

- Sirt

- $\mathrm{Dbc} 1$

Aumentan sólo la actividad de la grasa blanca

- Proteína morfogenética del hueso 8B

Abreviaciones: Sirt, sirtuina 1, Tbx15,T-box proteína 15, VEGF,factor de crecimiento endotelial vascular.

\section{Sistema beta adrenérgico}

La noradrenalina estimula la proliferación y la diferenciación de los adipocitos pardos en roedores. La administración crónica de noradrenalina aumenta la celularidad y la masa total ${ }^{(19)}$; al mismo tiempo aumenta la expresión de UCP1 ${ }^{(19)}$. Los receptores beta adrenérgicos son tres diferentes: $\beta 1, \beta 2, \beta 3$. Los $\beta 1$ y los $\beta 3$ regulan la proliferación y la diferenciación de los adipocitos pardos, mientras los receptores $\beta 2$ situados en los vasos, median el flujo vascular del TAP(19).

En los humanos, el papel de los receptores adrenérgicos no se ha estudiado extensamente, pero algunas investigaciones sugieren que los receptores $\beta 1$ y $\beta 2$ pueden regular la actividad de los adipocitos pardos en humanos ${ }^{(18,19)}$.

En síntesis, los diferentes subtipos de receptores adrenérgicos parecen tener papeles en común, sobrepuestos sobre el TAP y permanece sin definir si la proliferación, la diferenciación y la activación son dependientes de ciertos subtipos de receptores específicos ${ }^{(19)}$.

\section{Catecolaminas}

La noradrenalina tiene un efecto poderoso sobre el TAP, en adición a su efecto local como neurotransmisor. En los pacientes con feocromocitoma aperados, en la grasa periadrenal se detectó abundante tejido adiposo pardo, en comparación con controles sanos $^{(19)}$. El TEP con FDG, antes positivo, desapareció después de cirugía exitosa del feocromocitoma ${ }^{(19)}$.

\section{Hormonas tiroideas}

Las hormonas tiroideas regulan el TAP por vía endocrina y paracrina. Este tejido y los preadipocitos expresan altos niveles de DIO2, que convierten la T4 en la activa T3. La T3 aumen- 
ta la expresión de la UCP1 y el consumo de oxígeno en cultivo primario y en cultivo de preadipocitos derivados de células madres multipotentes ${ }^{(19)}$.

En vivo la administración periférica de hormonas tiroideas es menos clara, por lo que se necesitan más estudios.

Hasta el momento no se han publicado estudios que aclaren el papel jugado por las hormonas tiroideas sobre los adipocitos pardos.

\section{Esteroides sexuales}

En humanos, varias series han informado una mayor prevalencia de TAP en mujeres que en hombres ${ }^{(2,3)}$. La diferencia por sexo puede deberse a mayor sensibilidad de la mujer al frío y a una mayor capacidad de la mujer de activar los adipocitos pardos; se duda de esta explicación ${ }^{(19)}$ y se deben hacer estudios más profundos ${ }^{(19)}$.

\section{Nutrición}

En humanos, la relación entre el TAP y la nutrición es confusa ${ }^{(19)}$, existe alguna evidencia que sugiere la relación del TAP con la ingestión alimenticia, pero se necesitan más estudios en humanos para definir esta relación ${ }^{(19)}$.

\section{Otros factores endocrinos}

Recientemente, se identificaron el factor de crecimiento de los fibroblastos 21 (FGF21) y la irisina, dos hormonas que modulan la composición del TAP y del TAB. La administración farmacológica de estas dos hormonas regula la expresión genética del TAP en el TAB. El resultado de la adquisición de componentes de la grasa parda en la grasa blanca (TAB) aumenta el consumo de energía y activa la pérdida de peso en roedores ${ }^{(19)}$. Se sugirió la importancia de estas hormonas en humanos porque en un estudio reciente se demostró incremento de la secreción del FGF21, después de la exposición al frío en algunos voluntarios ${ }^{(19)}$. El FGF21 es una adipocina, secretada por el tejido adiposo pardo, mediada por la exposición al frío, lo cual identifica al TAP como un órgano endocrino ${ }^{(19)}$.

\section{Importancia metabólica del TAP en humanos}

Los hallazgos recientes de que la grasa parda se encuentra en la gran mayoría de los humanos, si no en todos, sustenta el papel metabólico invaluable del TAP en la vida adulta ${ }^{(4,7)}$ (tabla 2).

La significación metabólica del TAP puede deberse a su contribución a la pérdida de energía, determinante del balance energético ${ }^{(19)}$.

\section{TAP en relación con la adiposidad}

En humanos se ha evaluado la relación entre el peso corporal y la presencia del TAP en varios trabajos retrospectivos realizados con TEP. En estos estudios hubo una relación negativa entre la actividad de TAP y el índice de masa corporal ${ }^{(2,3,19)}$. El índice de masa corporal fue en promedio 2 a $3 \mathrm{~kg} / \mathrm{m}^{2}$ más bajo en los TAP positivos que en los negativos. En un estudio, 162 individuos sanos, TAP positivo, con edades entre los 2 y 73 años presentaron un índice de masa corporal, una grasa total, y una grasa abdominal más bajas, comparadas con aquellos con TAP negativos ${ }^{(19)}$.

En un estudio longitudinal de 145 pacientes, con tumores malignos; el peso corporal fue aproximadamente de $3 \mathrm{Kg}$ menor en los pacientes con TAP positivo. La diferencia en peso no se relacionó con el estado de malignidad. Otras experiencias han repetido estos resultados ${ }^{(3,4,6)}$.

No se conoce si la actividad del TAP es un efecto o causa de la pérdida de peso. Se sugiere que las obesidades mayores podrían actuar como protección térmica, reduciendo así la necesidad de la termogénesis producida por el TAP, por lo tanto se disminuiría la actividad de esta grasa. Existe evidencia de que la deprivación alimenticia aumenta la actividad del $\operatorname{TAP}^{(36)}$.

\section{TAP y la salud humana}

La inducción de la actividad del TAP en un ambiente frío puede tener implicaciones predecibles en la salud humana. La dependencia del balance nutritivo de la temperatura sugiere que la actividad termogénica del TAP es mayor en ambientes fríos que en calientes. El cambio de un ambiente frío a un termoneutral se ha calculado que puede llevar a un aumento anual hasta $4 \mathrm{~kg}$ de peso $^{(19)}$.

La evidencia del impacto del ambiente térmico sobre el peso corporal viene indirectamente de un estudio en roedores ${ }^{(19)}$. Estos animales se situaron en un ambiente a $22^{\circ} \mathrm{C}$, menor a la temperatura de $30^{\circ} \mathrm{C}$ a la que están acostumbrados, en un ambiente confortable. En estas condiciones, la actividad simpática aumentó con el fin de defender a estos roedores de la hipotermia. Se activó el metabolismo en respuesta a las condiciones subtérmicas ambientales. Después de un mes de convivir en este ambiente la grasa blanca adquirió algunas características de la grasa parda, lo que produjo la pérdida de un $70 \%$ de la masa adiposa, independiente de la actividad física y la dieta.

En el humano, para desgracia, es imposible repetir estas condiciones experimentables, ya que la raza humana moderna, excepcionalmente está expuesta continuamente a un ambiente por debajo de la termoneutralidad ${ }^{(19)}$. Dentro de las casas, la temperatura ha aumentado un $10 \%$, en algunos países, en los últimos 40 años, temperatura cercana a la termoneutralidad ${ }^{(19)}$. A esta temperatura ambiental, en menos del $10 \%$ de los pacientes a quienes se les practica un TEP se detecta grasa parda.

La civilización actual con las comodidades que las rodean raramente está expuesta a temperaturas frías durante largos períodos. 


\section{Posibilidades futuras}

El uso del TEP-TAC para estudiar la grasa parda en humanos es costoso y expone a la radiación. La irradiación combinada de TEP-TAC estándar excede las guías aceptadas de seguridad en voluntarios normales. Las gammagrafías TEP-TAC para estudios prolongados están restringidas para personas normales. Además porque la interpretación de las TEP-TAC es difícil de definir, ya que las imágenes obtenidas con esta técnica radiológica no diferencian el volumen de la activación de la grasa parda. Serían deseables métodos que fueran capaces de diferenciar el volumen y la actividad metabólica separadamente.

\section{Resonancia magnética}

Existen estudios que demuestran la posibilidad de obtener imágenes del volumen, la distribución y la actividad metabólica de la grasa parda en estados de reposo y en funcionamiento con imaginología obtenida con la resonancia magnética. La validación de este método podría aportar en humanos importantes datos sobre el estudio del adipocito pardo y su actividad ${ }^{(19)}$. Se necesita mayor estudio del TAP con este método.

\section{Imágenes térmicas}

El principio de las imágenes térmicas está basado en que el adipocito pardo es capaz de producir calor en la piel que cubre el tejido, por encima del obtenido en las zonas circundantes. Los dispositivos actuales para obtener imágenes térmicas son muy sensibles, capaces de captar diferencias de temperatura de $0,1^{\circ} \mathrm{C}$. La experiencia en humanos con esta termografía ha sido alentadora ${ }^{(19)}$. Se necesita mayor investigación al respecto.

\section{Estimuladores de la masa del TAP}

Se espera en un futuro que los conocimientos obtenidos sobre el TAP y su poder termogenético puedan utilizarse en beneficios terapéuticos, especialmente en los pacientes obesos, para lo cual se necesitarían estímulos apropiados para aumentar la masa y la actividad de los adipocitos pardos, lo cual se podría obtener incrementando el desacoplamiento respiratorio, la fundamental y única acción del TAP. A este respecto, el reclutamiento del adipocito brite dentro de los adipocitos blanco (TAB) sería una estrategia factible.

Con este fin se han ensayado diferentes métodos con resultados desiguales. Se ha sugerido que la activación de los agonistas beta adrenérgicos podría estimular la proliferación o activación de los adipocitos pardos, tales como la efedrina o el isoproterenol ${ }^{(19)}$. Estas dos drogas, con la exposición al frío, aumentaron el consumo de energía, pero no se presentaron efectos sobre la actividad de la grasa parda, como lo demostraron las imágenes negativas con el TEP-TAC.

Sin mediar el mecanismo, es improbable que la terapia adrenérgica pueda activar el TAP en la misma proporción que la exposición al frío. Al mismo tiempo, las dosis altas que se necesitan en humanos para obtener una imagen adecuada del TAP, presentan aumento de la presión arterial basal ${ }^{(19)}$, lo que limita su utilización como ayuda diagnóstica del TAP.

Como experimental se ha encontrado de utilidad para activar indirectamente el adipocito pardo una proteína ósea 8B y los compuestos capsinoides que aumentan discretamente el gasto de energía en pacientes con presencia de adipocitos $\operatorname{pardos}^{(19)}$.

\section{Grasa parda}

Estudios en animales sugieren que las células brite tiene un potencial completo para desarrollarse en adipocitos pardos maduros.

En el momento actual se conoce poco sobre el mecanismo de la conversión de la grasa blanca a parda. Entre los factores probables de esta trasformación en humanos están el FGF21 y la irisina, ya que actúan como hormonas y por la posibilidad potencial de ser producidas por el método del ADN recombinante. Si se comprueban estos hallazgos en humanos se abrirían serias posibilidades como terapia en ciertas condiciones como la obesidad ${ }^{(19)}$.

\section{Conclusiones}

Contrario a lo que se creía hasta ahora, la grasa parda está presente en el humano adulto y juega un papel regulador en el metabolismo energético. La comprensión parcial de la contribución del TAP en la termogénesis y su capacidad de ser inducida in vitro ha abierto la posibilidad de iniciar la investigación con proyectos bien dirigidos en la terapia de la obesidad.

La clasificación tradicional de los adipocitos, en blancos y pardos es una excesiva simplificación. Dentro del adipocito blanco se han identificado características histológicas y funcionales del adipocito pardo. La adipogénesis no solamente se refiere a un depósito específico sino a unas células específicas dentro de un depósito. 


\section{Referencias}

1. Cannon B, Nedergaard J, Brown adipose tissue: function and physiological significance. Physio Rev. 2004;84:277-359.

2. Cypess AM, Lehman S, Williams G, et al. Identification and importance of brown adipose tissue in adult humans. N Engl J Med. 2009; 360:1059-1517.

3. Lee P, Greenfield JR, Ho KK, et al. A critical appraisal of the prevalence and metabolic significance of brown adipose tissue in adults humans. Am Physiol Endocrinol Metab. 200;299: E601- E 606.

4. Lee P, Zhas JT, Swarbrick MM, et al. High prevalence of brown adipose tissue in adults humans. J Clin En Endocrinol Metab. 2011;96:2450-2455.

5. Virtaner KA, Lindell ME, Orava J, et al. Functional brown adipose tissue in healthy adults. N Engl J MEd. 2009:360:1518-1525.

6. Zingaretti Mc, Crosta F,Vitali A, et al. The presence of UCP1 demostrates that active adipose tissue in the neck of adult humans truly represents brown adipose tissue. Faseb. 2009; 23: 3113-3120.

7. vanMarker Lichtenbelt WD, Vanhommerig JW,Smulders NM, et al. Cold activated brown adipose in healthy men. N Engl J Med. 2009;360: 1500-1508.

8. Bouillaud F, Villarroya F, Hentz E, et al. Detection of brown adipose tissue uncoupling protein mRNA in adults patients by a human genomic prole. Clin Sci(Lond) 1988; 75: 21-27.

9. Bouillaud F, Combes- George M, Ricquier D. Mitondria of adult human brown adipose tissue contains a 32.00.Mr uncoupling protein. Biosci Rep. 1983; 3: 775-780.

10. Hatai S. On the presence in human embroys of an interscapular gland corresponding to the so- called hibernating gland in the lower animals. Anatomischer Anzeiger. 1902; xxi: 369.

11. Bonnot E. The Interscapular gland. J Anat Physiol. 1908; 43:43-58.

12. Rasmussen A. The glandular status of brown multilocular adipose tissue. Endocrinology. 1922;6:760-770.

13. Smith RE, Hock RJ. Brown fat : thermogenic effector of arousal in hibernators. Science. 1963; 140: 199-200.

14. Dawkins MJ, Scopes JW. Non_shiverning thermogenesis and brown adipose tissue in the human new- born infant. Nature. 1965;206:201-202.

15. Dawkins MJ, Hull D. Brown adipose tissue and the response of new-born rabbits to cold. J Physiol. 1964; 172:216-238.

16. Hull D. Th estructure and function of brown adipose tissue. Br Med Bull. 1966; 22: 92- 96.

17. Aherne W, Hull D. Brown adipose tissue and heat production in the newborn infant. J Pathol Bacteriol. 1966;91:223-234.

18. Silverman WA;Zamelis A, Sinclair JC, et al. Warm nap of the newborn. Pediatrics. 1964;33:984-987.

19. Lee p, Swarbrick MM, Ken K Y. HO. Brown adipose tissue in adults humans: A metabolic renaissance. Endocrine Review. 2013;34:413-438.

20. Smalley RL, Dryer RL. Brown fat : thermogenic effect during arousal from hibernation in the bat. Science. 1963;140:1333-1334.
21. Heaton JM. The distribution of brown adipose tissue in the human. J Anat. 1972;122:35-39.

22. Himms- Hagen J. Obesity may be due to a malfunctioning of brown fat. Can Med Assoc J. 1979; 121: 1361-1364.

23. Do the lucky ones burn off their dietary excess? Lancet 1979;2: 115-116.

24. Elliot J. Blame It all on brown fat now. JAMA. 1980; 243: 1983-1985.

25. Lindley M. Nutrition and metabolism. Nature. 1980; 287:579-580.

26. Rothwell Nj, Stock MJ. Brown adipose tissue: does it play a role in the development of obesity? Diabetes Metab Rev. 1988;4: 595- 601.

27. Astrup A, Bulow J. Christensen NJ, et al. Ephedrine- induced thermogenesis in man: no role for interscapular brown adipose tissue. Clin Sci (Lond). 1984; 66: 179-186.

28. Himms-Hagen J. Brown adipose tissue thermogenesis and obesity. Prog Lipid Res. 1989; 28: 67-115.

29. Ravussin E, Kozak LP. Have we entered the brown adipose tissue renaissence? Obese Rev. 2009;10: 265-268.

30. Gesta S, Tseng YH, Kahn CR.Developmental origen of fat: tracking obesity to its source. Cell. 2007;131:242-256

31. Rousseau V, Becker DJ, Ongemba LN, et al. Developmental and nutritional changes of ob and PPAR 2 gene expressions in rat white adipose peroxisone tissue. Biochem J. 1997;321:451-456.

32. Braissant 0 , Wahli W. Differential expression of peroxisome proliferator activated receptor- $\alpha,-\beta$ and $-\gamma$ during rat embrionic development. Endocrinology. 1998; 139:2748-2754.

33. Hansen JB, Kristiansen K. Regulatory circuits controling White versus brown adipocyte differentiation. Biochem J. 2006; 398; 153- 168.

34. Rosen ED. MacDougald OA. Adipocyte differentiation from the inside out Nat Rev Moll Cell Biol. 2006;7:885-896.

35. Néchad M, Kuusela P, Carneheim C, et al. Development of brown fat cells in monolayer culture. Morphological and biochemical distinction from White fat cells in culture. Exp Cell Res. 1983;149:105-118.

36. Hu E, Tontonoz P, Spiegelman BM. Transdifferentiation of mioblast by the adipogenic transcription factors PPAR $\gamma$ and C/EBP $\alpha$. Proc Natl Acad Sci U S A.1995;92:9856-9860

37. Puigserver P, Wu Z, Park CW, et al. A cold imducible coactivador of nuclear receptors linked to adaptive thermogenesis. Cell. 1998;92:829-839.

38. Kleiner S, Mepani RJ,Laznik D, et al. Development of insulin resistance in mice lacking PGC- $1 \alpha$ in adipose tissue. Proc Natl Acad Sci USA 2012;109:9635-9640.

39. Pardo R,Enguix N, Lasheras J, et al. Rosiglitazone- induced mitocondrial biogenesis in White adipose is independent of peroxisome proliferator- activated receptor $\gamma$ coactivator-1 $\alpha$. PLoS One. 2011;6: e 26989.

40. Seale P, Kajimura S, Spiegelman BM. Transcriptional control of brown adipocyte development and physiological function: of mice and men.Genes Dev.2009;23:788-797. 